\title{
Bortezomib/Liposomal Doxorubicin Regimen
}

National Cancer Institute

\section{Source}

National Cancer Institute. Bortezomib/Liposomal Doxorubicin Regimen. NCI Thesaurus.

Code C136263.

A chemotherapy regimen consisting of bortezomib and liposomal doxorubicin that is used for the treatment of plasma cell myeloma. 